ALPHA No 29 Diciembre 2009 (55-66)

ISSN 0716-4254

http://alpha.ulagos.cl

\title{
LA DESMATERIALIZACIÓN DEL ORDEN FAMILIAR Y LA FIGURA DEL PADRE EN CUANDO ÉRAMOS INMORTALES DE ARTURO FONTAINE T.
}

The dematerialization of the family order and the father figure in Cuando éramos inmortales, by Arturo Fontaine $\mathrm{T}$.

Carmen Gloria Godoy R.*

La combinación de poder y dolor es la historia secreta de la vida de los hombres, la experiencia contradictoria del poder entre ellos. Michael Kimmel

Resumen

Lectura de la novela Cuando éramos inmortales (1998) del escritor chileno Arturo Fontaine Talavera a partir de la configuración de la imagen paterna y de la masculinidad. Cuando éramos inmortales se desarrolla en el Chile de la década de los sesenta del pasado siglo, una época de importantes transformaciones culturales, sociales y políticas, entre ellas, la progresiva desaparición de las estructuras agrarias tradicionales. En la novela se narra la transformación de la familia, un referente fundamental de la vida social de la época. Desde la mirada del protagonista en dos momentos de su vida —infancia y adolescencia — vemos cómo, junto a la “caída” de la hacienda, se va produciendo también la desmaterialización del orden familiar tradicional y de la figura del padre en el espacio privado.

Palabras clave: Literatura chilena, familia, paternidad, masculinidad.

Abstract

This work is a reading of Arturo Fontaine's novel, Cuando éramos inmortales (1998). The essay proposes a reading from the configuration of the paternal image and masculinity. Cuando éramos inmortales occurs in Chile, in the decade of the sixties, a time of important cultural, social and political transformations, including the progressive disappearance of the traditional agrarian structures of. The novel narrates the transformation of family, a central element of the social life of those years. From the viewpoint of the protagonist as a child and teenager, we are witnessing the collapse of the "hacienda", and the dematerialization of the order and the family father figure in the private space.

Key words: Chilean literature, family, paternity, masculinity. 
Carmen Gloria Godoy R.

\section{INTRODUCCIÓN ${ }^{1}$}

El período que se abre en Chile a principios de la década de los noventa con la reinstalación de un régimen de gobierno de carácter democrático ha sido analizado desde diversos ángulos. ${ }^{2}$ En términos culturales, Jorge Larraín señala que esta década constituye un escenario que dio forma a nuevos valores e identidades, inscritos en la lógica del libre mercado. El clima cultural de los noventa marcado por "el neoliberalismo, la globalización, la economía de mercado, la creciente mediatización de la cultura, la despolitización y la modernización” (2001:164) se traduce en una producción literaria en que el realismo mágico, la naturaleza, la sociedad rural, la política de izquierda o la identidad latinoamericana son desplazados por problemáticas de otra índole, propias del mundo privado y de una sociedad despolitizada (2001:165-166) si bien esta tendencia no se expresaría de la misma manera y en todos los autores del período señalado por Larraín. ${ }^{3}$

Me importa destacar de Larraín la lectura de este desplazamiento de lo público a lo privado, un tránsito hacia problemáticas como las relaciones familiares, la infancia, la maternidad y la paternidad que dialogan con las transformaciones de las relaciones sociales de género en el espacio público. ${ }^{4}$ A fines de los noventa fueron publicadas dos antologías de autores nacionales, cuyos relatos giraban en torno a la maternidad y a la paternidad. ${ }^{5}$ Por otra parte, varias novelas abordaron experiencias como el Golpe de Estado, la dictadura militar y - en fechas más recientes - el cambio de siglo y el gobierno de Ricardo Lagos E., a partir de los fracasos personales (asociados a proyectos políticos) las rupturas familiares, los quiebres en las relaciones de pareja y la relación entre padres e hijos. En Machos tristes (1992) Darío Oses

${ }^{1}$ Este trabajo se basa en la ponencia "La desmaterialización del orden familiar y la figura del padre, en Cuando éramos inmortales”, presentada a las Jornadas Andinas de Literatura Latinoamericana (JALLA, Santiago, 11 al 15 de agosto 2008). Se inscribe, también, en el Proyecto Fondecyt N 1060018 (marzo 2006 - marzo 2009). "Paternidad en Chile en las clases populares, medias y superiores en el medio urbano”, dirigido por Ximena Valdés S.

${ }^{2}$ Cfr. Estudios de Tomás Moulian (1998), Eugenio Tironi (2005) y José Bengoa (2006).

3 Tendencia que se encontraría en autores como Alberto Fuguet, Sergio Gómez, Gonzalo Contreras y Arturo Fontaine T., si bien para Larraín los dos últimos serían literariamente superiores.

${ }^{4}$ Leonor Arfuch advierte la creciente importancia de la experiencia persona (del "yo") en la cultura contemporánea y sus diversas manifestaciones. Hace notar que la dicotomía público/ privado ya no constituye dos espacios mutuamente excluyentes, sino una intersección que opera en ambas direcciones. De tal manera que "no sólo lo íntimo/privado saldría de cauce invadiendo territorios ajenos, sino, también, lo público —en sus viejos y nuevos sentidos, lo político, lo social, lo de uso, interés y bien común, etc. - tampoco alcanzará todo el tiempo el estatuto de la visibilidad (...)" (2002:76).

${ }^{5}$ Ver Salidas de madre (1996) y Honrarás a tu padre (1998). 
narra la experiencia de la Unidad Popular y los últimos días de la dictadura desde la mirada de los "derrotados", encarnada en dos funcionarios de la Universidad de Chile, mientras se encuentra intervenida por los militares. Roberto Brodsky, en Últimos días de la historia (2001) trata sobre el significado que adquiere la experiencia del Golpe y el exilio para dos amigos de la infancia y en Bosque Quemado (2007) aborda la relación entre padre e hijo en el marco del exilio. De igual manera, Pablo Simonetti ha abordado las relaciones familiares, la subjetividad masculina y la homo-sexualidad en el escenario del Chile de comienzos del siglo XXI.

Por esta razón, resulta interesante explorar la forma como se expresan los imaginarios de familia y paternidad en la producción literaria chilena de la última década, y cómo esta ilumina la comprensión de algunos aspectos de los cambios en los discursos y prácticas en torno a dichos temas. De igual manera, cabe explorar la constitución discursiva de la subjetividad masculina, a partir de las representaciones de la paternidad. Esto, porque una de las repercusiones que ha tenido el desarrollo de la teoría del género es la "problematización de la identidad masculina" en la medida que se ha hecho explícito que también los hombres están sujetos a procesos sociales y culturales que ponen a lo masculino en una posición de dominación material y simbólica, así como de subordinación por razones como la raza, la etnia o la clase. Como señala R. W. Connell, la masculinidad es "un aspecto de una estructura mayor" que se asocia a contradicciones y rupturas históricas (1997:31).

Desde hace ya más de una década, los estudios sobre masculinidad han adquirido una importancia creciente en Latinoamérica y en Chile, dando cuenta del proceso de reconfiguración al que se enfrenta el modelo de masculinidad hegemónica ante las transformaciones del lugar de las mujeres en el espacio público y de las representaciones y prácticas de género en el ámbito privado (Fuller, 2004; Olavarría, 2001-2002-2004; Valdés y Godoy, 2008). Según José Olavarría (2002) el modelo de masculinidad hegemónico se sostiene sobre la base de la constitución de una familia y la paternidad, junto con el ejercicio de la autoridad y la provisión material, que concede y asegura la autoridad del varón al interior de la familia. Pero factores de índole económica, social, política e, incluso, religiosa, han influido en los cambios en los roles de género y en las representaciones sociales de lo masculino y de lo femenino durante este último tiempo. El informe del PNUD del año 2002 mostró la tensión que producía esta representación en la familia y en la relación entre tradición y cambio cultural. En general, las relaciones entre familia y sociedad se han vuelto problemáticas, las exigencias que impone la sociedad a las familias dificultan el cumplimiento de lo que las personas 


\section{Carmen Gloria Godoy R.}

perciben como su misión: su influencia en la definición de las identidades personales y la concreción de proyectos de vida (2002:205-206).

Estos cambios se han manifestado en el plano de las representaciones socio-culturales. Desde la última década en Chile han comenzado a aparecer nuevas representaciones sobre la familia y la paternidad. Las producciones dramáticas televisivas ${ }^{6}$ han incorporado diversidad de formas familiares, combinando la imagen paterna - ya sea la del padre autoritario o la de un padre afectuoso y comprensivo- con la de una mujer profesional, autónoma e independiente económicamente. Eugenio Tironi considera que el éxito este tipo de producciones tiene que ver con un interés por la "interacción emotiva" de las personas que reemplaza el interés por la política y la economía y que coincide con un proceso de apertura de la sociedad chilena en torno a temas "conflictivos y dolorosos, como el 11, la corrupción en el Estado, la conducta de algunos sacerdotes, el comportamiento privado de las celebridades, las redes de pedofilia, y así por delante. Todo lo cual se ha desplegado no en la plaza pública, ni menos en los salones de políticos o aulas de intelectuales, sino en la intimidad de los hogares, frente a las pantallas de la TV” (2005: 204).

Los datos obtenidos en una investigación sobre paternidad entre distintos grupos sociales indican, además, que "los mayores cambios se observan en la subjetividad masculina que incorpora al hijo/a en la construcción de la individualidad y, por lo tanto, nuevas relaciones de filiación llegan a conformar parte significativa de las identidades masculinas" (Valdés y Godoy, 2008:106). En estas representaciones se observan rupturas intergeneracionales y atributos "vinculados a la cercanía afectiva y la comunicación con los hijos, frente al padre autoritario, violento, distante y lejano, pero sostén económico de la familia, según sea el caso de las definiciones que den los entrevistados de los distintos grupos sociales” (2008:106). En suma, el lugar y los significados del padre en el imaginario

\footnotetext{
${ }^{6}$ Hago referencia a las teleseries Machos (segundo semestre 2003) y a Papi Ricky (primer semestre 2007) del Canal 13 de la Pontificia Universidad Católica de Chile. La primera tenía como eje de la trama a una familia tradicional de clase alta, narrada desde la perspectiva masculina: la de los siete hermanos Mercader cuyo padre era un hombre autoritario y represor. La telenovela tocaba superficialmente el tema de la homosexualidad, a través de uno de los hermanos, y resultó ser muy exitosa en términos de audiencia. Papi Ricky, por su parte, abordaba también la problemática familiar pero desde la perspectiva de la monoparentalidad. Sus personajes protagónicos eran un padre joven y atractivo y su hija de 8 años, fruto de una relación de juventud con una mujer de la cual se desconoce inicialmente su identidad. El reconocimiento entre madre e hija era un elemento importante en el desarrollo de la historia y aumentaba la tensión dramática. Sin embargo, el eje estaba puesto en la relación de complicidad que se establecía entre Ricky y Alicia, la niña.
} 
habrían sufrido una mutación, pero así también la masculinidad hegemónica, al menos discursivamente.

Como señalaba, quisiera abordar estos cambios a través de la ficción literaria, específicamente en relación a Cuando éramos inmortales de Fontaine Talavera. Se trata de un texto donde la masculinidad se vuelve un objeto de reflexión, a partir del cruce de la experiencia personal y los acontecimientos históricos, en este caso, la Reforma Agraria y la etapa previa al triunfo de la Unidad Popular. Estos acontecimientos configuran diversos escenarios y experiencias en los que se va desarrollando la "biografía emocional" del protagonista y que exponen su intimidad y sus deseos y, también, la desorganización de la familia tradicional y la desestabilización de los cimientos de la autoridad paterna.

Cuando éramos inmortales se desarrolla en el Chile de la década de los sesenta del pasado siglo, época cuando se inician importantes transformaciones culturales, sociales y políticas, entre ellas la progresiva desaparición de las estructuras agrarias tradicionales y la redefinición de los roles de género. Desde la mirada del protagonista sobre dos momentos de su vida —infancia y adolescencia - asistimos al derrumbe del orden hacendal y, junto con él, la desmaterialización del orden familiar tradicional y la figura del padre en el espacio privado. Sin embargo, en una entrevista A. Fontaine afirma que esta es una historia que trasciende la cuestión de clase, para dar cuenta de una problemática contemporánea: la falta de certezas. Se trata, dice, de una novela de formación, pero donde el personaje protagónico en lugar de avanzar hacia un "puerto seguro" que le permita "construir su personalidad", se mueve hacia la incertidumbre (en línea). ${ }^{7}$

La novela va recreando el tránsito de la niñez a la adolescencia de Emilio Carvajal, el hijo menor de una familia de latifundistas, cuyo padre se divide entre su trabajo como profesional -ingeniero calculista en una empresa constructora - y el destino ya incierto del fundo familiar del cual ha debido hacerse cargo, a pesar suyo. La madre se dedica al cuidado de los hijos y a la supervisión de las tareas de la casa. En el fondo, se trata de familia austera descendiente de esa antigua oligarquía apegada a los valores de una sociedad tradicional en la que los hijos asisten a un colegio católico y no al colegio inglés como sus primos, más caro y más moderno, pero cuyo proyecto educativo no se sostiene en la religión. Se trata, fundamentalmente, de un mundo masculino, habitado y visitado por algunas mujeres: la abuela, la madre, las primas, las empleadas de la hacienda. En ese relato se entrecruzan la narración directa e indirecta de los acontecimientos que se van sucediendo:

\footnotetext{
${ }^{7}$ Fontaine señala que en Chile existe una gran producción literaria en torno a lo femenino, no así respecto a lo masculino, algo que pretende subvertir con su novela.
} 


\section{Carmen Gloria Godoy R.}

la ruptura matrimonial de los padres de Emilio, la aparición de otros hombres en la vida de la madre, la soledad del padre y la violencia física y psicológica entre compañeros, ignorada por las autoridades del colegio. En este sentido, Emilio transita por tres espacios simbólicos y materiales que van modelando su identidad: la hacienda, la casa y la escuela. Me centraré en los dos primeros.

El relato se inicia con las últimas temporadas en las tierras familiares, que una noche serán expropiadas producto del proceso de reforma agraria. La “disolución” del orden hacendal modifica las identidades de los habitantes de ese mundo, que deja de ser espacio de reconocimiento mutuo para convertirse en pura perplejidad. Sin embargo, para Emilio este hecho cobrará sentido a la luz de la separación de sus padres, mientras los acontecimientos históricos van siendo desplazados hacia los márgenes del relato. En ese contexto, la subjetividad masculina despliega una conflictividad que va prefigurando el escenario social que se instaurará tiempo después, con la violencia del Golpe de Estado, escenario marcado, también, por la tensión entre el liberalismo económico y el conservadurismo ideológico de los miembros de la antigua elite, y el arribo de una nueva clase empresarial. Pero, nuestra lectura aborda fundamentalmente la relación padre e hijo.

\section{EL ORDEN FAMILIAR Y EL LUGAR DEL PADRE}

Desde la perspectiva de Cornelius Castoriadis, el gran problema que enfrentan las sociedades occidentales es continuar "siendo capaces de fabricar el tipo de individuo necesario para la continuidad de su funcionamiento" (1997:25). Con ello, Castoriadis hace referencia a la familia — nuclearcomo "primera y principal” fábrica de individuos, en tanto la crisis de la familia contemporánea se encuentra en el derrumbe y en la desintegración de los roles tradicionales, lo cual revela un proceso de autonomía y una emancipación en ciernes, pero de consecuencias ambiguas asociadas al problema de la autorrepresentación de la sociedad. Esto es, la representación de la sociedad como algo para sí misma, "un sí mismo singular y único, nombrado (referible) pero, por otra parte, "indefinible”, al que los individuos pertenecen porque participan "en las significaciones imaginarias sociales, en sus "normas”, “valores”, “mitos”, "representaciones”, "proyectos”, "tradiciones", etc., y porque comparten (lo sepan o no) la voluntad de ser de esta sociedad y de hacerla ser continuamente” (1997:28). Podríamos agregar, el problema del sentido.

Cabe señalar que, en términos históricos, los modelos familiares han ido cambiando en función de los procesos de urbanización e industrialización y al poder que fue adquiriendo el Estado moderno en la vida de los individuos 
frente a la disminución del poder religioso en el ámbito económico y político (Castelain, 2002:49-62). ${ }^{8}$

Desde la perspectiva psicoanalítica, Elizabeth Roudinesco señala que nuestra época ha generado profundos trastornos en la familia y en la figura del padre. Roudinesco analiza la evolución de la familia desde la perspectiva del padre y el ejercicio de la autoridad, para llegar a decir que hoy nos enfrentamos a una "familia mutilada", "hecha de heridas íntimas, violencias silenciosas, recuerdos reprimidos” (2002:21). La familia moderna se habría “desacralizado" progresivamente, al mismo tiempo que "de manera paradójica seguía siendo la institución humana más sólida de la sociedad” (2002:21). Con dicha desacralización, el poder del antiguo pater familias sobre la prole habría quedado en suspenso para dar origen al "patriarca mutilado". El padre tiene una imagen invertida de sí, dejando ver "un yo descentrado, autobiográfico, individualizado, cuya gran fractura intentará asumir el psicoanálisis a lo largo de todo el siglo XX” (2002:21).

Estas perspectivas resultan útiles para la comprensión de la desestructuración del orden familiar tradicional en la novela - evidentemente con algunos matices relativos a cuestiones históricas y culturales - y del lugar que ocupa el padre, ya que su figura resulta ser bastante más precaria frente al modo que lo representa como autoridad y sostenedor exclusivo de la familia, efectivamente más allá del contexto de clase y de la matriz tradicional.

\section{DESESTRUCTURACIÓN DEL ORDEN FAMILIAR Y LA FIGURA DEL PADRE}

En Cuando éramos inmortales la figura del padre va tomando forma mediante una alternancia de la narración directa e indirecta, que conjuga la voz del Emilio niño y la del Emilio adulto, que así reconstruye la experiencia de su infancia y le otorga sentido desde el presente. En ese ejercicio, la imagen de Salvador (el padre) emerge como la de un hombre de mediana edad que decae progresivamente, tanto como el orden que lo sostiene. Salvador es un sujeto que no se dedica completamente al ejercicio de su profesión. Está atado a un pasado que debe sostener aunque ya no rinda frutos; sea porque no

${ }^{8}$ Respecto a Cuando éramos inmortales, el sociólogo Carlos Cousiño señalaba que la modernización de las estructuras económicas remeció esa suerte de orden primigenio que era la hacienda, produciendo una crisis de valores, de manera tal que sólo una vez que los hijos de la elite "restauren" el antiguo orden se producirá la conciliación de los valores tradicionales y el de los intercambios económicos. Los "Emilios", portadores de la sustancia de este mundo, volverán a su lugar lo que los intereses economicistas destruyeron. Para Cousiño, lo que permite ver esta novela "es precisamente lo que no pueden todos aquellos autores que vieron la crisis del orden agrario como crisis de la oligarquía: comprender por qué esa elite no desapareció, sino que fue ella la que rearmó posteriormente las estructuras del Chile moderno” (1999:13). 


\section{Carmen Gloria Godoy R.}

puede o no desea enfrentar el cambio. Olga, la madre, lo define como un burgués que se cree aristócrata, que se afana por mantener el fundo pese a que, en realidad, vive de sus ingresos como profesional

¿A qué fin querer mantener ese fundo? Año que no daba pérdidas descorchábamos una botella de champaña. (...) Y se sentía "agricultor", y los educó a ustedes convencido de que habían nacido para ser patrones... (...) ¿Y para qué? ¿Para que su madre no echara de menos el mundo de su juventud, el que vivió con su marido y sus niñitos con casona de hacienda y capataces y mozos de cuadra? ¿Para que él pudiera seguir imaginándose que era su padre? ${ }^{9}$

En el contexto de esas nuevas representaciones del padre a las que hacía referencia, uno de los elementos más sugerentes es la importancia de las sensaciones y de las emociones en la descripción de la relación filial, muy lejana a la imaginación del padre construida exclusivamente desde el ejercicio de la autoridad

El día comenzaba con el olor del fósforo (...) Era el fósforo con que mi papá encendía el califont del pasillo antes de ducharse. Usaba una bata de levantarse de lana cuyo escocés desvaído se adivinaba apenas y que olía entera a papá. No sabía a qué olía mi papá. Pero si sé que impregnaba su bata un olor que también le permitía distinguir, en el baño, y sin lugar a dudas, cuál era su toalla y cuál la de mamá (...)

Y en aquella época Emilio quería a su papá sin saber que lo quería, y él lo quería sin pedir nada a cambio. Las exigencias corrían por cuenta de su madre (...) (44).

Esta percepción del padre y su reconstrucción a través de fragmentos, de las sensaciones más físicas de la primera infancia, se conjuga con la de los lugares y los objetos materiales que le pertenecen: su sillón, su lámpara de lectura, los discos de música clásica. Porque un día el padre ya no está, y esta ausencia produce un quiebre profundo en el mundo de Emilio. Informado de su partida, comenzará a buscarlo precisamente en esos espacios, donde han quedado sus huellas, intentando recuperar su presencia en la casa, invocando su imagen cada vez que siente miedo

(...) muchas veces, cuando vuelve del colegio y antes de hacer las tareas y antes de que vuelva su mamá del trabajo, porque mi mamá trabaja ahora, yo pongo los discos que mi papá todavía no se ha llevado al

${ }^{9}$ Arturo Fontaine T. Cuando éramos inmortales. Santiago: Alfaguara, 1998:92. Citaremos por esta edición. 
departamento. Y voy tratando de acordarme. Pero no podría preguntarle a mi papá qué música había en el living entonces. Soy el único que abre ahora la puertecita de la Grundig para poner un disco (40-41).

Una vez que el quiebre matrimonial se hace definitivo, Salvador abandona la casa familiar y Emilio se ve enfrentado al ejercicio de recuperar su presencia, a pesar de compartir los fines de semana el nuevo espacio que habita un pequeño departamento. Emilio debe reconstruir al padre a través de múltiples imágenes en que las tierras familiares se constituyen como un espacio deseado en la medida que posibilitarían el reencuentro familiar y no necesariamente la restauración del poder económico

(...) mi papá ya no saca su llavero lleno de sonidos entrechocándose que me transportaban a las diferentes puertas de su vida: la oscura bodega del fundo pasada a roble y a vino; el chirriante portón de fierro forjado del parque; la puerta plana, blanca, lisa del departamento que se abría al olor de la alfombra apelmazada; la puerta de vidrio esmerilado con el logo de la firma de ingenieros en rojo y negro; la puerta hermética y de acero de la vieja caja fuerte del fundo cuya cerradura emitía al cerrarse sonidos tan precisos, misteriosos, definitivos. Desde que estábamos separados extrañaba esas puertas. Me pregunto cuando nos encontraremos de nuevo todos juntos en el fundo (118-119).

A medida que avanza la narración, el padre es trasladado a otro plano, su presencia material se va diluyendo y la adolescencia vuelve la mirada de Emilio hacia sus iguales, sus compañeros de colegio pero, también, hacia Ricardo, un nuevo hombre, la nueva pareja de la madre que también es padre. Ricardo es descrito como un intelectual de izquierda, gran conversador, entretenido, pero que "representa una inserción" en la trama de la vida de Emilio. Invade su casa, su refugio, con sus aromas, su presencia y parece apropiarse de todos los espacios. "En el baño, su agua de colonia, sus hojas de afeitar usadas, su frasco de pastillas para dormir” (320). Ricardo relativiza el orden familiar desde una racionalidad aparente que normaliza la excepcionalidad de la experiencia de Emilio, la separación de sus padres. Pero, además, habla como un "observador imparcial, como si él no perteneciera a ninguna de las clases que le gusta tanto analizar” (331). No se piensa a sí mismo desde los códigos que se manejan en el mundo de Emilio. Los mismos y los únicos códigos que maneja su padre, que lo han dejado atado a un mundo que se cae a pedazos, pero que no está dispuesto a transar para sobrevivir a los nuevos tiempos

(...) no sé leer los signos de los tiempos y ya no queda espacio histórico para un señor como yo, tal como ya no lo hay para un caballero feudal, 


\section{Carmen Gloria Godoy R.}

(...) simplemente no tengo futuro (...) ¿Qué es al fin y al cabo, un hombre como tu padre, Emilio? Un quiltro... Ni aristócrata castellano ni indio, ni cosmopolita ni exótico, ni tan pobre ni tan rico, ni tan de aquí ni tan de allá... ¿Sabes, Emilio? No somos representativos de nadie ni de nada. (...) un viejo señor chileno como yo, un terrateniente de manta de vicuña, no puede nacer de nuevo y hacerse proletario (...) (312).

Y de la misma manera como el padre empieza a perder su lugar en el mundo social, así también va diluyéndose la imagen del padre en la experiencia de Emilio y en el espacio familiar

Nos habíamos acostumbrado él y yo, a vivir irremediablemente separados. El umbral de la casa de mi madre era el umbral donde vivía otro hombre (...) mi padre entonces ya había muerto; y él lo sabía. Pero todavía quizás era posible resucitar por un ratito. Porque, seguramente por la separación, por ese irse viendo cada día menos, no supo ir cambiando conmigo a medida que yo crecía; no le fue posible seguir inventando nuevos personajes para acompañar a los sucesivos Emilios que iban surgiendo en ese tiempo. Tampoco el hijo supo percibir al padre. Se me quedó congelado. No fue capaz de ir recreando esos vínculos (348-350).

La mirada protectora del padre que salva a Emilio de sí mismo y del juicio de los otros, desaparece también. La distancia física se traduce en distancia emocional. El padre se ha quedado como tal en la infancia de Emilio; como un refugio mientras debe acostumbrarse a la idea de tener que mirarse sólo con sus propios ojos. "Yo, dice el padre, todavía no sé bien qué es lo que soy” (301). Sin embargo, sí tendría una certeza que desea transmitir a su hijo como resultado de su experiencia y esta es valorar la belleza de la vida y la importancia del amor en cualquiera de sus expresiones.

En este sentido, más allá de la nostalgia por la desaparición de la hacienda, y la interpretación de las relaciones entre campesinos y patrones, que desliza sutilmente los conflictos de clase, me parece que uno de los elementos más sugerentes de la novela es, justamente, esta deconstrucción de la figura del padre. La imagen totalizadora del padre omnipotente a los ojos del hijo debe dejar paso a la de un hombre que no tiene clara conciencia de su identidad, más bien, queda desprovisto de ella en la medida que el orden social que conocía se desarma. Ese padre no sobrevive ni a las transformaciones sociales que traen consigo la Unidad Popular ni a la dictadura. Si bien sobre ninguna de las dos se hace referencia como tal, ellas aparecen entre sombras, sea en la escena de una peña en el centro de la ciudad y en la imagen de Ricardo que representa la oleada modernizadora y secularizadora; o en la 
prefiguración de escenas de violencia y abusos entre los compañeros de colegio. Carlos Cousiño interpreta la disputa amorosa entre Ricardo y Salvador por la madre de Emilio como una disputa por el poder (la "prenda sexual garantiza prestancia social” (1999:13) que luego será resuelta por los herederos de la elite. Digamos, entonces, que esos hombres que ingresan al orden de Salvador para disputar el poder constituirían sólo una inserción en la trama de la Historia, más tarde expulsados o, al menos, subordinados al poder económico de sus “verdaderos" protagonistas.

Pero lo que viene después tampoco asegura la permanencia de Salvador en esa trama histórica. En Salvador habita un orden que, a pesar de los intentos restauradores de la dictadura, también se hizo difuso. Las rupturas y contradicciones históricas, como plantea Connell (1997), van modelando las identidades de género y los significados de la familia. Ante la pérdida de las certezas, como el mismo Fontaine señala, y más allá de la diferencia de clases, el padre, como figura de autoridad absoluta e incuestionable, habría desaparecido para dejar lugar al hombre que debe aprender a ejercer su paternidad despojado del entramado simbólico y material en el que se sostenía.

\author{
Universidad Diego Portales* \\ Facultad de Ciencias Sociales e Historia \\ Av. Ejército 333. C. P.: 8370127. Santiago (Chile) \\ cggodoy82@hotmail.com
}

\title{
BIBLIOGRAFÍA
}

ARCOS, René., et al. Honrarás a tu padre. Santiago: Planeta, 1998.

ARFURCH, Leonor. El espacio biográfico. Dilemas de la subjetividad contemporánea. Buenos Aires: F. C. E., 2002.

BENGOA, José. La comunidad reclamada. Identidades, utopías y memorias en la sociedad chilena actual. Santiago: Catalonia, 2006.

BRODSKY, Roberto. Bosque quemado. Buenos Aires: Mondadori, 2008. Últimos días de la historia. Santiago: B, 2001.

CASTELAIN, Christine. La place des hommes et les métamorphoses de la famille. Paris: Presses Universitaires de France, 2002.

CASTORIADIS, Cornelius. "La crisis de las sociedades occidentales", en El avance de la insignificancia. Buenos Aires: EUDEBA, 1997.

CONNELL, R. W. "La organización social de la masculinidad”, en Valdés, Teresa y José Olavarría. (Eds.). Masculinidad/es. Poder y Crisis. Santiago: Las Mujeres N²4/ Isis Internacional (1997):31-48. 
Carmen Gloria Godoy R.

COUSIÑO V., Carlos. "Las virtudes de Emilio. Sobre la novela Cuando Éramos Inmortales”, en El Mercurio, Cuerpo E (3 Oct. 1999):13.

FONTAINE T., Arturo. "Arturo Fontaine en Vuelan las Plumas: "No me siento representante de nadie”. 26 Oct. 2003. Radio Universidad de Chile. 10 Mar. 2009. <http://www.letras.s5.com/vlp4.htm>

------ Cuando éramos inmortales. Santiago: Alfaguara, 1998.

FULLER, Norma. "Identidades en tránsito: femineidad y masculinidad en el Perú actual”, en Norma Fuller. (Ed.) Jerarquías en Jaque. Estudios de género en el área andina. Lima: Red para el Desarrollo de las Ciencias Sociales en el Perú/CLACSO, 2004.

LARRAÍN, Jorge. Identidad chilena. Santiago: LOM, 2001.

MOULIAN, Tomás. Chile actual. Anatomía de un mito. Santiago: ARCIS, 1998.

OLAVARRÍA, José. “¿Dónde está el nuevo padre?” (Trabajo doméstico: de la retórica a la práctica), en Ximena Valdés y Teresa Valdés. (Eds.). Familia y vida privada. ¿Transformaciones, tensiones, resistencias o nuevos sentidos? Santiago: FLACSO/CEDEM, 2004.

- "Hombres: identidades, relaciones de género y conflictos entre trabajo y familia”, en José Olavarría y Catalina Céspedes. (Eds.). Trabajo y familia: ¿Conciliación? Perspectivas de género. Santiago: SERNAM/ FLACSO/ CEM, 2002.

------- Y todos querían ser buenos padres. Santiago: FLACSO, 2001.

ORELLANA, Carlos (Ed.). Salidas de madre. Santiago: Planeta, 1996.

OSSES, Darío. Machos Tristes. Santiago: Planeta, 1992.

PROGRAMA DE LAS NACIONES UNIDAS PARA EL DESARROLLO (PNUD). Informe de desarrollo humano en Chile. Nosotros los chilenos: un desafío cultural. Santiago: 2002.

ROUDINESCO, Elizabeth. La familia en desorden. Buenos Aires: F. C. E., 2002.

SIMONETTI, Pablo. La razón de los amantes. Santiago: Planeta, 2007.

TIRONI, Eugenio. El sueño chileno. Comunidad, familia y nación en el Bicentenario. Santiago: Aguilar Chilena, 2005.

VALDÉS S., Ximena; GODOY, Carmen Gloria. "El lugar del padre: rupturas y herencias. Representaciones de la paternidad en grupos altos, medios y populares chilenos". Estudios Avanzados. Instituto de Estudios Avanzados (IDEA)/Universidad de Santiago. 6(9) (2008):79-112. 